\title{
Antioxidant and Membrane Stabilizing Activities of Bark of Sonneratia apetala
}

\author{
Md. Emdadul Hasan Mukul ${ }^{1,2}$, Mohammad Salim Hossain'1, Sayed Koushik Ahamed ${ }^{1,3}$, \\ Pankaj Debnath ${ }^{1}$ and Mariyam Akter ${ }^{1}$ \\ ${ }^{1}$ Department of Pharmacy, Noakhali Science and Technology University, Sonapur, Noakhali-3814, Bangladesh \\ ${ }^{2}$ Department of Pharmacy, Khwaja Yunus Ali University, Enayetpur, Sirajgonj-6751, Bangladesh \\ ${ }^{3}$ Department of Pharmacy, Comilla University, Comilla, Bangladesh
}

Received: March 06, 2016; Accepted: April 10, 2016; Published (Web): July 31, 2016

\begin{abstract}
This study was carried out to investigate the antioxidant activity in terms of free radical scavenging capacity and membrane stabilizing ability of methanol extract of bark of Sonneratia apetala. The total phenol content of the extract was measured by Folin-Ciocalteu reagent. The antioxidant potential was investigated using 2,2 diphenylpicrylhydrazyl (DPPH), reducing power assay and chelating power determination. The membrane stabilizing capacity was assessed by monitoring the hypotonic solution - and heat-induced haemolysis of human erythrocytes. The total phenolic content was found $50.75 \mathrm{mg} / \mathrm{gm}$ of gallic acid equivalent. The extract exhibited significant antioxidant activity in DPPH free radical scavenging assay with IC $_{50}$ value of 81.42 $\mu \mathrm{g} / \mathrm{ml}$ as compared to the standard, $\mathrm{BHT}\left(\mathrm{IC}_{50}=42.56 \mu \mathrm{g} / \mathrm{ml}\right), \mathrm{Fe}^{2+}$ ion reducing power assay and chelating power ability. In case of assay for chelating ability, EDTA represented $98.76 \%$ chelation while the plant extract showed $82.83 \%$ at concentration of $100 \mu \mathrm{g} / \mathrm{ml}$. In addition, the methanol extract of bark of this plant was found to moderately inhibit the haemolysis of human erythrocyte. In conclusion, the methanol extract of $S$. apetala could be valuable candidate for future development for antioxidant activity.
\end{abstract}

Key words: Sonneratia apetala, Phenolic content, Free radical scavenging activity, Chelation, Reducing power.

\section{Introduction}

During the oxidative stress, various reactive oxygen species (ROS) like superoxide, hydroxyl and peroxyl radicals are generated. These ROS play important role for the pathogenesis of several health problems like cancer, Alzhimer's disease (Ames, 1983; Gey, 1990; Smith et al., 1996), cellular aging (Finkel, 2000), diabetes (Stadler, 2012), and inflammation (Aruoma, 1998). Thus minimizing the effect of these free radicals is important for the maintaining a healthy life (Davies, 2000). Human beings are using plants to treat various illnesses for thousand of years and discovery of new medicines from plant sources has been always a major area of research (Samuelsson, 2004). Antioxidants from natural sources have gained benefits of having better efficacy with less side effects.
Sonneratia is a plant genus of plants having 20 identified species in the family of Lythraceae. $S$. apetala Buch.-Ham. is found in Bangladesh, Sri Lanka, Myanmar, and India, including the Andaman and Nicobar islands. It has been introduced into Fujian and Guangdong provinces of China. S. apetala is a highly adaptable, fast growing plant that acts as a pioneer species in ecological succession in many degenerated mangrove forests (Chen et al., 2003). The fruits of $S$. apetala are extensively consumed by the coastal people of Bangladesh for antidiabetic, antibacterial and antioxidant capacities (Hossain et al, 2013). Thus, we aimed to study the total phenolic content and free radical scavenging activity related to antioxidant capacity and membrane stabilizing ability of the bark of

Correspondence to: Mohammad Salim Hossain; Tel: + 88-01711-200-410; Email: pharmasalim@ yahoo.com 
S. apetala and we, here in, report the results of our preliminary investigations.

\section{Materials and Methods}

Drugs and chemicals: 1,1-Diphenyl-2-picrylhydrazyl (DPPH), ascorbic acid, quercetin and gallic acid were obtained from Sigma Chemical Co (MO, USA). Folin- ciocalteu reagent (FCR) was purchased from Merck, Germany. All other chemicals and reagents were of analytical grade.

Extraction: The plant S. apetala is locally known as kewra. The bark of $S$. apetala was collected from Sundarban, in February, 2013 with the help of local people. A specimen has been kept in our laboratory for future reference. After drying and crushing, the powdered material $(500 \mathrm{gm})$ was fully soaked into methanol $(2.5 \mathrm{~L})$ and allowed to stand for 15 days with occasional shaking and stirring. The extract was filtered and solvents were evaporated to dryness.

Determination of total phenol content: Total phenol content of $S$. apetala extract was measured as per published method by employing Folin-Ciocalteu reagent (Foiln and Ciacalteu, 1927). Total phenolic content in the plant extract was expressed in terms of gallic acid equivalent ( $\mathrm{mg} / \mathrm{gm}$ of dry mass), which is a common reference compound.

DPPH free radical scavenging activity: The DPPH oxidative assay is used worldwide in the quantification of radical scavenging capacity. The antioxidant activities of plant extracts and the standard were assessed on the basis of the free radical scavenging effect of the stable DPPH free radical activity described by Monzarro et al (1998). Here, BHT was used as standard. The following equation was used to calculate the scavenging activity. 100

$$
\text { DPPH scavenged }(\%)=\left\{\left(\mathrm{A}_{\text {control }}-\mathrm{A}_{\text {test }}\right) / \mathrm{A}_{\text {control }}\right\} \mathrm{x}
$$

where, $\mathrm{A}_{\text {control }}$ is the absorbance of the control reaction and $A_{\text {test }}$ is the absorbance in the presence of the test sample.

Reducing power assay: The reducing power of the extract was determined by the method described by Benzie and Strain (1999). Briefly, various concentrations of the plant extract in $1.0 \mathrm{ml}$ deionized water were mixed with potassium ferricyanide $(2.5 \mathrm{ml})$ in phosphate buffer and incubated for $20 \mathrm{~min}$ at $50^{\circ} \mathrm{C}$. Trichloroacetic acid $(2.5 \mathrm{ml})$ was added to this mixture and allowed to centrifuge at $3000 \mathrm{rpm}$ for $10 \mathrm{~min}$. The upper layer of the solution $(2.5 \mathrm{ml})$ was mixed with distilled water $(2.5 \mathrm{ml})$ and freshly prepared ferric chloride solution $(0.5 \mathrm{ml})$ and the absorbance was measured at $700 \mathrm{~nm}$ using ascorbic acid as standard. Reducing power was calculated by using the following equation:

$\%$ Increase in the reducing power $=$

$$
\left\{\left(\mathrm{A}_{\text {test }} / \mathrm{A}_{\text {blank }}\right)-1\right\} \times 100
$$

Chelating power ability: The chelation of ferrous ions by extracts was estimated by method of Dinis et al. (1986). Briefly, $50 \mu \mathrm{l}$ of $2 \mathrm{mM} \mathrm{FeCl}_{2}$ was added to $1 \mathrm{ml}$ of various concentrations of extract. The reaction was initiated by addition of $0.2 \mathrm{ml}$ of $5 \mathrm{mM}$ ferrozine solution. The mixture was vigoriously shaken and allowed to stand at room temperature for $10 \mathrm{~min}$. The absorbance of the solution was thereafter measured at $562 \mathrm{~nm}$. Here EDTA was used as standard. The chelating power was determined by using the following equation:

$$
\begin{aligned}
& \% \text { Inhibition of ferrozine- } \mathrm{Fe}^{2+} \text { complex }= \\
& {\left[\left(\mathrm{A}_{0}-\mathrm{A}_{\mathrm{s}}\right) / \mathrm{A}_{\mathrm{s}}\right] \times 100}
\end{aligned}
$$

where, $A_{0}$ was the absorbance of the control, and $\mathrm{A}_{\mathrm{s}}$ was the absorbance of the extract.

Membrane stabilizing activity: The membrane stabilizing activity was assessed using hypotonic and heat-induced hemolysis of human erythrocyte by the method developed by Shindhe et al. (1999) with slight modification by Sikder et al. (2011). The result was compared with standard, acetyl salicylic acid.

\section{Result and Discussion}

Antioxidants play important roles in the defense mechanism of human body and help to minimize the oxidative stress caused by the reactive oxygen species (Davies, 2000). There is growing interest in the antioxidant activity of plant materials. Estimation of total phenolic contents is the first step to determine the antioxidant capacity of plant extract. Here we assessed 
the total phenolic content of the extractive, which was found to be $50.75 \mathrm{mg}$ of GAE/gm.

Several studies have indicated that the antioxidant activities of some plants are highly correlated with their total phenolic contents (Palave et al., 2006; Gupta et al., 2010). Taking this into consideration, the antioxidant activity of this extract was assessed. The results are presented in figure 1 .

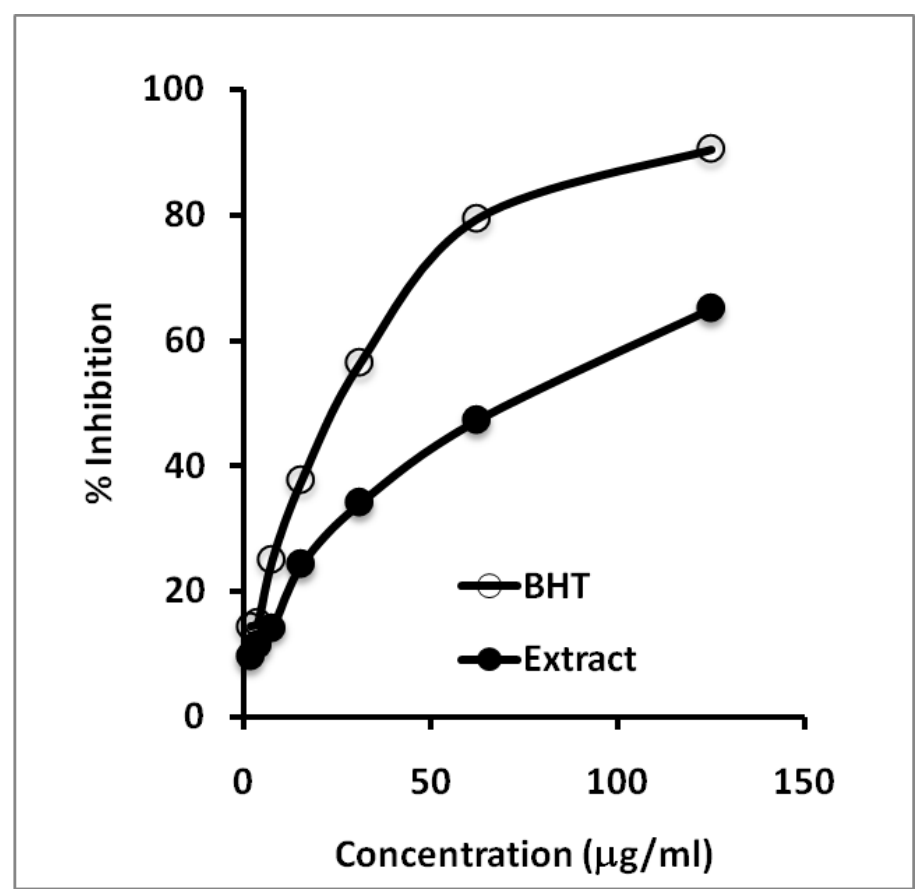

Figure 1. DPPH scavenging activity of bark of $S$. apetala.

In case of DPPH scavenging activity, $\mathrm{IC}_{50}$ value of the extractive was $81.42 \mu \mathrm{g} / \mathrm{ml}$, whereas the standard BHT showed $\mathrm{IC}_{50}$ value of $42.56 \mu \mathrm{g} / \mathrm{ml}$. The linearity range of calibration curve was $2 \mu \mathrm{g} / \mathrm{ml}$ to $125 \mu \mathrm{g} / \mathrm{ml}\left(R^{2}\right.$ $=0.939$ for extract and $R^{2}=0.851$ for BHT). Although, the extent of inhibition was less than that of BHT, the test extractive was shown to have a good DPPH scavenging activity.

Furthermore, as the $\mathrm{Fe}^{+2}$ reducing power is also considered to be a parameter to address the antioxidant activity, the reducing power capability of the extractive was estimated. The results presented in figure 2 shows that the reducing power of the extractive was seen to increase as a function of concentration. The reducing power of the extract was compared with ascorbic acid. Although, at lower concentration, the extract showed the fairly similar absorbance with that of the standard, it was evident that the extract was less potent that ascorbic acid to reduce the $\mathrm{Fe}^{+2}$ at higher concentration.
Moreover, another mechanism of antioxidative action is chelation of transition metals, thus preventing catalysis of hydroperoxide decomposition and Fenton type reactions (Gordon, 1990). In the presence of chelating agents, the complex formation is disrupted with the reduction of the red color of the complex. Measurement of color reduction, therefore, allows the estimation of the chelating activity of the coexisting chelator. The transition metal ion, $\mathrm{Fe}^{2+}$ possesses the ability to move single electrons by virtue of which it can allow the formation and propagation of many radical reactions, even starting with relatively nonreactive radicals (Aboul-Enein et al., 2003). The result of chelation assay is presented in figure 3. At concentration of $5 \mu \mathrm{g} / \mathrm{ml}$, EDTA showed $36.97 \%$ chelating ability, where as the plant extract displaced $24.08 \%$. On the other hand, at $100 \mu \mathrm{g} / \mathrm{ml}$ concentration, EDTA represented $98.76 \%$ chelation, as compared to $82.83 \%$ by the plant extract. All these data agree with the strong chelating ability of bark of $S$. apetala. 


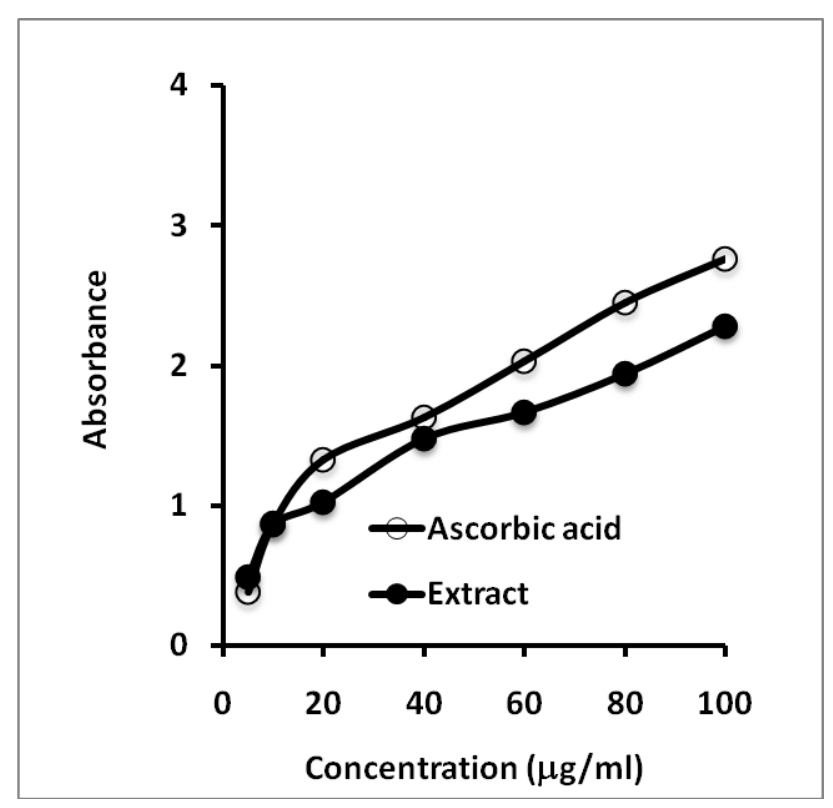

Figure 2. Reducing power assay of S. apetala.

The anti-inflammatory potentials of the crude extract was assessed through the membrane stabilizing activity by using acetyl salicylic acid as positive control. Membrane stabilization is well studied as a mechanism of anti-inflammatory response (Shinde et al., 1999). Our data (Table 1) revealed that the methanolic extract of $S$. apetala has moderate inhibitory

Table 1. Membrane stabilizing effect of bark of S. apetala.

\begin{tabular}{lcc}
\hline Treatment & \multicolumn{2}{c}{ \% Inhibition of haemolysis } \\
\cline { 2 - 3 } & $\begin{array}{c}\text { Hypnotic solution } \\
\text { induced }\end{array}$ & $\begin{array}{c}\text { Heat } \\
\text { induced }\end{array}$ \\
\hline $\begin{array}{l}\text { Acetyl salicylic acid } \\
\text { (Standard) }\end{array}$ & $77.3 \pm 1.45$ & $61.5 \pm 0.46$ \\
$\begin{array}{l}\text { Extract of Sonneratia } \\
\text { apetala }\end{array}$ & $56.0 \pm 1.76$ & $42.5 \pm 1.45$ \\
\hline
\end{tabular}

capacity of haemolysis of erythrocyte in hypotonic solution- and heat-induced conditions. As erythrocyte membrane is similar to lysosomal membrane components, it is extrapolated that the drugs which stabilizes erythrocyte membrane can also stabilizes lysosomal membrane (Omale et al., 2008) and thus interfere with the release and or action of mediators responsible for inflammation like histamine, serotonin,

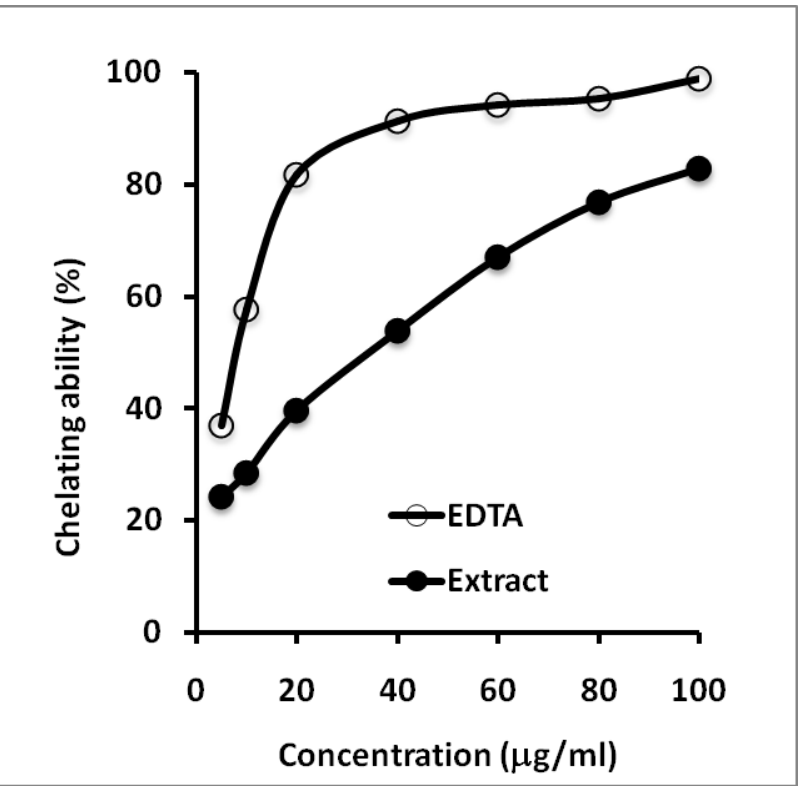

Figure 3. Chelating ability of bark of $S$. apetala.

prostaglandins, etc. (Shinde et al., 1999). Thus, the test extract may be considered to be moderately effective to inhibit the release of inflammatory mediators.

\section{Conclusion}

The present study suggests that, the methanolic crude extract of bark of $S$. apetala possesses potential free radical scavenging, reducing power, chelating abilities and moderate inhibitory effect on membrane stabilization. Further studies are necessary to isolate the specific active compounds from the bark of $S$. apetala and elucidate the mechanism of action.

\section{Acknowledgement}

The research was partly supported by a grant (BS 142/2012) obtained from Ministry of Science and Technology, Government of The Peoples' Republic of Bangladesh.

\section{References}

Aboul-Enein, A.M., El Baz, F.K., El-Baroty, G.S., Youssef, A.M., and Abd El-Baky, H. H. 2003. Antioxidant activity of algal extracts on lipid peroxidation. J. Med. Sci. 3, 87-98.

Ames, B.N. 1983. Dietary carcinogens and anticarcinogens: oxygen radicals and degenerative diseases. Science. 221, 1256-1264. 
Aruoma, O.I. 1998. Free radicals, oxidative stress and antioxidants in human health and disease. J. Am. Oil. Chem. Soc. 75, 99-212.

Benzie, I.F.F. and Strain, J.J. 1999. Ferric reducing/ antioxidant power assay: direct measure of total antioxidant activity of biological fluids and modified version for simultaneous measurement of total antioxidant power and ascorbic acid concentration. Methods Enzymol. 299, 15-27.

Chen, Y., Liao, B., Peng, Y., Xu, S., Zheng, S., and Chen, D. 2003. Researches on the northern introduction of mangrove species Sonneratla apetala Buch.-Ham. Guangdong Forest. 19, 9-12.

Dinis, T.C.P., Madeira, V.M.C., and Almeida, M.L.M. 1986. Action of phenolic derivates (acetoaminophen, salycilate and 5-aminosalycilate) as inhibitors of membrane lipid peroxidation and as peroxyl radical scavengers. Arch. Biochem. Biophys. 315, 161-169.

Davies, K.J.A. 2000. Oxidative stress, antioxidant defenses and damage removal, repair and replacement systems. IUBMB Life. 50, 279-289

Finkel, T. 2000. Oxidants, oxidative stress and the biology of aging. Nature 408, 239-248.

Folin, O. and Ciocalteu, V. 1927. On tyrosine and tryptophane determination in proteins. J. Biol. Chem. 27, 627-650.

Gey, K.F. 1990. The antioxidant hypothesis of cardiovascular disease: epidermiology and mechanisms. Biochem. Soc. Trans. 18, 1041-1045.

Gordon, M.H. 1990. The mechanism of the antioxidant action in-vitro. In: B.J.F. Hudson (Ed.), Food Antioxidants. Elsevier London/New York, pp. 1-18.

Gupta, P.K., Langridge, P., and Mir, R.R. 2010. Markerassisted wheat breeding: present status and future possibilities. Mol. Breed. 26, 145-161.
Hossain, S.J., Basar, M.H., Rokeya, B., Arif, K.M.T., Sultana, M.S., and Rahman, M.H. 2013. Evaluation of antioxidant, antidiabetic and antibacterial activities of the fruit of Sonneratia apetala (Buch.-Ham.) Oriental Pharm. Exp. Med. 3, 95-102.

Manzorro, L., Anese, M., and Nicoli, M.C. 1998. Antioxidant properties of tea extracts as affected by processing. Lebens- mittel-Wissenschaft Und-Technol. 31, 694-698.

Omale, J., and Okafor, P.N. 2008. Comparative antioxidant capacity, membrane stabilization, polyphenol composition and cytotoxicity of the leaf and stem of Cissus multistriata. Afr. J. Biotechnol. 7, 3129-33.

Palave, Y.K., and D'mello, P.M. 2006. Standardization of selected Indian medicinal herbal raw materials containing polyphenols as major phytoconstituents. Ind. J. Pharm. Sci. 68, 506-509.

Samuelsson, G. 2004. Drugs of Natural Origin: A Text of Pharmacognosy. 4th revised ed., Swedish Pharmaceutical Press, Stockholm, Sweden, pp. 417-429

Shindhe, U.A., Phadke, A.S., Nair, A.M., Mungantiwar, A.A., Dikshit, V.J. and Saraf, M.N. 1999. Membrane stabilizing activity - a possible mechanism of action for the anti-inflammatory activity of Cedrus deodara wood oil. Fitoterapia. 70, 251-257.

Sikder, M.A., Rahman, M.A., Kaisar, M.A., Rahman, M.S., Hasan, C.M. and Rashid, M.A. 2011. In vitro Antioxidant, reducing power, free radical scavenging and membrane stabilizing activities of seeds of Syzygium cumini L. Lat. Am. J. Pharm. 30, 781-785.

Smith, M.A., Perry, G., Richey, P.L., Sayre, L.M., Anderson, V.E., Beal, M F. and Kowal, N. 1996. Oxidative damage in Alzheimer's disease. Nature 382, 120-121.

Stadler, K. 2012. Oxidative stress in diabetes. Adv. Exp. Med. Biol. 771, 272-287. 